\title{
Jurist-Diction
}

Volume 4 No. 2, Maret 202

\section{Pertanggungjawaban Pidana Pelaku BDSM (Bondage, Discipline, Sadism and Masochism) yang Mengakibatkan Luka, Cacat atau Kematian}

\author{
Elok Fauzia Dwi Putri
}

elok.fauzia.dwi-2017@fhunair.ac.id

Universitas Airlangga

How to cite:

Elok Fauzia Dwi Putri

'Pertanggungjawaban

Pidana Pelaku BDSM

(Bondage, Discipline, Sadism and Masochism) yang

Mengakibatkan Luka, Cacat atau Kematian' (2021) Vol. 4

No. 2 Jurist-Diction.

Histori artikel:

Submit 11 Januari 2021;

Diterima 9 Februari 2021;

Diterbitkan 1 Maret 2021.

DOI:

10.20473/jd.v4i2.25781

p-ISSN: $2721-8392$

e-ISSN: $2655-8297$

\section{c) (1) (2)}

\begin{abstract}
Early this time, BDSM was widely discussed in social media and in everyday life. Many people are interested and curious to just know or dive into the world of BDSM. Curiosity and lack of knowledge can cause harm, injury, disability or death to BDSM scene partners. BDSM is not a criminal act although it is closely related to violence because it is carried out with consent. In psychology, sadism and masochism are included in paraphilia. However, this deviation cannot be used as an excuse to abort the sentence because it is not one of the things that are excluded in Article 44 of the Criminal Code. Thus, BDSM perpetrators who cause injuries, disabilities and loss of life will still be sentenced. Keywords: BDSM; Criminal Liability; BDSM as a Crime.
\end{abstract}

\begin{abstract}
Abstrak
Dini ini, BDSM banyak dibicarakan dalam media sosial maupun dalam kehidupan sehari-hari. Banyak masyarakat yang tertarik dan penasaran untuk sekadar mengetahui atau terjun dalam dunia BDSM. Rasa penasaran dan kurangnya pengetahuan dapat menyebabkan kerugian seperti luka, cacat atau kematian kepada partner BDSM scene. BDSM bukan merupakan tindak pidana walaupun sangat erat kaitannya dengan kekerasan karena dilakukan dengan consent. Dalam ilmu kejiwaan, sadisme dan masokisme termasuk dalam parafilia. Namun, penyimpangan tersebut tidak dapat dijadikan sebagai alasan untuk menggugurkan pemidanaan dikarenakan bukan termasuk yang dikecualikan pada Pasal 44 KUHP. Sehingga, pelaku BDSM yang menyebabkan luka, cacat dan hilangnya nyawa akan tetap dipidana.

Kata Kunci: BDSM; Pertanggungjawaban Pidana; BDSM Sebagai Tindak Pidana.
\end{abstract}

\section{Pendahuluan}

Istilah mengenai BDSM masih terdengar asing bagi sebagian masyarakat. BDSM sendiri singkatan dari Bondage and Discipline, Sadism and Masochism. Definisi secara lengkapnya, BDSM adalah ketertarikan aktifitas seksual atau fantasi seksual yang mengarah dan melibatkan siksaan, pukulan, mengikat 
dengan tali dan menggunakan alat bantuan seksual dalam berhubungan seksual. Dalam BDSM ada 3 jenis hubungan yaitu Bondage and Discipline (BD), Domination and Submission (DS), serta Sadism and Masochism (SM). ${ }^{1}$ BDSM dilakukan penuh dengan tanggungjawab dan kehati-hatian. Tidak semua orang dapat melakukan BDSM. Peminat yang masih awam harus didampingi oleh yang lebih berpengalaman agar permainan tetap sesuai rules dan aman. Selain itu, BDSM mengedepankan sifat consensual yaitu setiap partisipan harus saling menghormati batas yang telah diterapkan satu sama lain. $^{2}$

Sewajarnya, BDSM dilakukan secara berpasangan dengan kesepakatan. Namun, dalam beberapa kasus, BDSM mengalami penyelewengan baik dengan cara pemaksaan, maupun dilakukan secara berlebihan kemudian timbul penganiayaan hingga menghilangkan nyawa. BDSM akan sangat mengerikan apabila tidak dipahami secara mendetail. Perlakuan dan efek luka yang ditimbulkan dalam berhubungan seksual dianggap sadis dan berbahaya. Padahal menurut peminatnya, justru aktifitas-aktifitas kasar itulah yang dapat menghantarkan kepada kenikmatan. Faktor tidak lumrahnya hal tersebut dilakukan pada aktifitas seksual yang notabene memberikan kasih sayang bukan perlakuan kasar.

\section{Metode Penelitian}

Penelitian ini menggunakan tipe penelitian normatif. Penelitian normatif merupakan penelitian yang berdasar pada suatu sumber utama yang menelaah konsep, asas dan norma-norma yang berkaitan dengan tema terkait. Biasanya, penelitian normatif disebut juga dengan penelitian kepustakaan yang cara mengumpulkan datanya dengan menganalisis sumber kepustakaan baik primer maupun sekunder sehingga penelitian ini bersifat preskriptif.

1 Nicholas R., 'Arisan 11! BDSM', (Support Group and Resource Center on Sexuality Studies, 27 September 2015), < http://sgrcui.wordpress.com>, diakses pada tanggal 7 Agustus 2020.

2 ibid. 


\section{Konsep dan Batasan dalam BDSM}

BDSM scene tidak selalu berkaitan dengan hubungan seksual yang berhujung penetrasi. Scene yang diciptakan bisa saja hanya dalam bentuk permainan, penghantar sebelum penetrasi atau sebagai bagian (dilakukan bersamaan) dari penetrasi itu sendiri. Biasanya, BDSM scene dilakukan dengan role play yang dibagi menjadi dua yaitu top dan bottom. Top merupakan istilah untuk seseorang yang memberikan perlakuan atau sadomasokis (dominant, master, caregiver, owner, riger, sadist, degrader, brat tamer, primal) dan bottom adalah seseorang yang menerima perlakuan atau masokis (submissive, slave, little, pet, rope bunny, masochist, degradee, brat, primal).

"In BDSM practices, quite often we play a role that is related to power. I don't mean "play" to be insulting to those who consider D/s or M/s to be something integral. What I mean is that sometimes we ramp up the power differential for periods of time to have fun. It might be a lecturer/student, Master/slave or soldier/prisoner scene". ${ }^{3}$

Orang awam atau orang yang tidak memiliki ketertarikan terhadap BDSM, merasa dan mengira perbuatan tersebut kasar, melukai dan tidak sewajarnya dilakukan untuk memuaskan hasrat. Namun bagi peminatnya, mereka melakukan BDSM scene sejatinya untuk kepuasan dan kebahagiaan pribadi. Mereka merasakan sakit, namun sakit itu lah yang mereka cari untuk menemukan kenikmatan.

"We enjoy that moment of becoming a particular person in our world of imagination, and our partner helps us to bridge the world of fantasy and imagination into reality, by consenting to be slapped by (or to slap) you. We're no longer a Master, Dom, slave or sub "in theory", we become that in a real social interpersonal interaction in society". 4

BDSM scene tidak dapat dilakukan sembarangan. Ada beberapa cara agar BDSM dapat dilakukan dengan aman. Untuk pemula, baiknya mempelajari BDSM melalui berbagai sumber tertulis terlebih dahulu untuk memperbanyak ilmu dan meyakinkan diri apakah ia benar-benar tertarik untuk melakukan atau hanya sekedar penasaran dengan BDSM tersebut. Kemudian, Hendaknya memiliki

3 Boy Denon, 'BDSM as an Art Form', (Deviance \& Desire, 19 Februari 2016), <https://www. devianceanddesire.com/2016/02/bdsm-as-an-art-form/>, diakses pada 15 Oktober 2020.

4 ibid. 
mentor seorang senior praktisi BDSM untuk memberi saran dan penambahan referensi. Atau dapat pula dengan memiliki seorang trainer yang memberikan edukasi sekaligus mengajarkan skill secara langsung, tata cara maupun tingkah laku. Trainer dapat memiliki hubungan (ownership) dengan yang diajarkan atau bisa saja tanpa memiliki hubungan (ownership).

Selain itu, perlu diketahui bahwa keyword dalam BDSM adalah SSC (safe Sane and Consensual). Akhsa Astharisha Kezia dalam akun intagramnya@aksha.kezia menjelaskan safe atau keamanan yang dimaksud adalah mengetahui batas aman diri kita sendiri dalam bermain BDSM. Baik limitasi diri kita sendiri dalam merasakan sakit, resiko maksimal yang dapat kita terima, mengetahui seberapa jauh ilmu yang kita pahami maupun yang dipahami oleh partner bermain dan cara menanggulangi resiko yang kemungkinan kita dapatkan. Untuk sane adalah kemampuan para pelaku BDSM untuk dapat mengontrol penuh dirinya, bertanggung jawab dan dapat melakukan penilaian situasi dengan baik. Dikarenakan BDSM membutuhkan kontrol yang lebih, BDSM scene diharapkan tidak dilakukan dibawah pengaruh alkohol, obat-obatan terlarang maupun dengan kondisi mental yang tidak stabil.

Sebelum berkomitmen pada ownership BDSM, sangat penting untuk dilakukan diskusi antar partner agar BDSM scene berjalan dengan aman. Yang pertama adalah negosiasi. Negosisasi merupakan bagian dari komunikasi yang menjadi kunci utama dalam BDSM. Dalam negosiasi dapat mengusulkan, menolak maupun menawarkan apa saja yang diinginkan selama BDSM scene terjadi. Bahkan dapat dimungkinkan dalam negosiasi didapatkan hasil untuk jangka panjang.

"Giving your consent and receiving a partner's consent is part of the process of negotiating a kink scene. Negotiation creates a space for everyone to talk about their needs, wants, limits, fantasies, and fears before they play. One way to begin the negotiation process is to identify what role or roles you will take on: top/bottom/switch, Dominant/submissive, sadist! masochist. Together you can go through some possible activities; for each one, you can decide if you are interested in doing it and whether you want to give or receive or both". 5

5 Tristan Taormino, Ultimate Guide to Kink (Cleiss Press 2015).[17]. 
Permintaan dan penolakan bersifat dua arah. Yang menjadi dominan maupun submisi dapat melakukan tawar menawar tanpa ada rasa tertekan. Hal-hal apa saja yang membuat trauma, sensitif terhadap suatu barang atau phobia terhadap sesuatu dapat pula dikatakan ketika sesi negosiasi.

Agar BDSM scene berjalan dengan kontrol yang baik dan terkendali, diciptakan safe word untuk memberi batasan ketika sudah merasa cukup, mengalami rasa sakit atau menginginkan untuk memberhentikan permainan. Safe word biasanya disebut juga dengan red flag. Safe word tidak memiliki ketentuan yang baku. Masingmasing pasangan dapat mengkreasikan sendiri dan tentunya didisusikan dalam sesi negosiasi. Contoh dari safe word misal penyebutan "red" untuk berhenti dan "yellow" untuk pelan-pelan.

Selain negosiasi dan komunikasi, yang paling utama adalah consent atau persetujuan. Consent dibutuhkan untuk mengetahui bahwa kedua belah pihak setuju untuk melakukan BDSM scene dengan senang hati dan tanpa rasa terpaksa.. Consent dibuat dengan keadaan sadar dengan kemauan diri sendiri tanpa dipengaruhi orang lain, alkohol maupun obat-obatan terlarang. Dengan adanya consent, menghilangkan kata penyiksaan, terpaksa atau melakukan perbuatan yang menyebabkan perasaan tersakiti. BDSM tanpa adanya consent dapat dikatakan sebagai pemaksaan, pemerkosaan dan sexual assault. "Consent-explicit, informed verbal approval after negotiation, a confident and secure "Yes! "-is the bedrock of sex and relationships, and one of the most significant elements of kink. It's what separates kink from abuse". ${ }^{6}$

\section{Kualifikasi BDSM sebagai Tindak Pidana}

Meskipun perlakuan dalam praktek BDSM menggunakan kekerasan, sejatinya BDSM dengan kekerasan seksual adalah hal yang berbeda. Seperti yang telah dijelaskan sebelumnya, BDSM dilakukan dengan persetujuan dan perjanjian. Mereka yang berada dalam ikatan perjanjian untuk BDSM scene telah menyusun

6 ibid.[26]. 
aturan-aturan tentang roleplay, safe word dan batasan-batasan lain yang telah disetujui kedua belah pihak. Berbeda dengan kekerasan seksual yang dilakukan dengan tidak adanya persetujuan diantara kedua belah pihak. Menerapkan masokis atau sadomasokis kepada orang lain secara terpaksa, tidak dapat disebut BDSM melainkan kekerasan seksual. Pada intinya, yang menjadi kunci pembeda antara BDSM dengan kekerasan seksual yang melibatkan fetisisme masokis dan sadomakis adalah consent.

Segala bentuk pukulan, tamparan maupun luka yang dihasilkan dari BDSM tidak bisa disebut sebagai kriminal. Namun lain pula apabila perbuatan menyiksa tersebut dilakukan untuk tujuan memaksa dengan penganiayaan maka digolongkan sebagai kekerasan seksual dan dapat dipidanakan. Atau hal tersebut terjadi apabila perlakuan-perlakuan dalam BDSM scene yang tidak sesuai dengan perjanjian atau ketika perlakuan dari salah satu peran hilang kontrol sehingga terlalu menyakiti lawannya dan menimbulkan rasa sakit, cacat bahkan dapat menyebabkan kematian. Lebih detailnya, berikut tanda yang dapat dikenali ketika BDSM sudah mengarah ke kekerasan antara lain: ${ }^{7}$

a. Menimbulkan kerusakan fisik atau mental, dan atau emosional, atau untuk menyakiti orang lain;

b. Sepenuhnya mengambil alih kuasa dari orang lain;

c. Tidak saling mengetahui, tidak ada satupun yang pernah bernegosiasi atau menyatakan persetujuan mengenai tindakan yang dilakukan;

d. Menciptakan kekhawatiran dan ketakutan pasangan;

e. Menghancurkan kepercayaan dan rasa mempercayai dalam bentuk apapun;

f. Melakukan tindakan kejahatan dan kekerasan ke orang lain.

BDSM scene yang erat hubungannya dengan sadomakisme dan sadisme memiliki batasan sangat tipis antara fetisisme dan penganiayaan. Sadomasokisme disebut juga algolagni pasif; sedangkan sadisme disebut juga algolagni aktif. ${ }^{8}$ Sadomakisme dan sadisme erat hubungannya dengan perlakuan yang menyebabkan luka pada

\footnotetext{
7 Tim CNN Indonesia, 'Mengenali Beda BDSM dan Kekerasan Seksual', (CNN Indonesia, 29 Februari 2020), <https://www.cnnindonesia.com/gaya-hidup/20200225151318-284-477975/ mengenali-beda-bdsm-dan-kekerasan-seksual>, diakses pada 7 Agustus 2020.

8 DR.Y.A. Triana Ohoiwutun, 'Ilmu Kedokteran Forensik (Interaksi dan Dependensi Hukum pada Ilmu Kedokteran)’, (2017), Repository Universitas Jember (online).[53].
} 
partner. Dalam KUHP, sadomakisme dan sadisme dapat dikatakan sebagai tindak pidana apabila menyebabkan hal-hal sebagai berikut:

a. Apabila BDSM menyebabkan luka akibat penganiayaan (diluar consent)

BDSM memang erat kaitannya dengan perlakuan yang mengarah pada penyiksaan terhadap seseorang, namun apabila perbuatan tersebut diluar apa yang diperjanjikan, dapat dikualifikasikan sebagai tindak pidana dan dapat dikenai Pasal 351 KUHP dan 352 KUHP. Pasal 351 KUHP berbunyi sebagai berikut:

1) penganiayaan diancam dengan pidana penjara paling lama dua tahun delapan bulan atau pidana denda paling banyak empat ribu lima ratus rupiah;

2) Jika perbuatan mengakibatkan luka-luka berat, yang bersalah diancam dengan pidana penjara paling lama lima tahun;

3) Jika mengakibatkan mati, diancam dengan pidana penjara paling lama tujuh tahun. Pasal 351 ayat (4) penganiayaan disamakan dengan sengaja merusak kesehatan.

Masokisme dan sadisme dapat dikenai Pasal 351 KUHP dikarenakan sengaja merusak kesehatan dengan penganiayaan dan menyebabkan luka sehingga deliknya dapat dipersamakan dengan delik Pasal 351 KUHP. Seseorang yang mendapatkan luka dalam BDSM scene dapat melakukan penuntutan dengan bukti luka atau cacat yang ada di tubuhnya (ada laporan dari pihak lain apabila menyebabkan mati). Pasal 352 KUHP menentukan penganiayaan yang tidak mengakibatkan penyakit atau halangan untuk menjalankan pekerjaan jabatan atau pencarian, diancam, sebagai penganiayaan ringan, dengan pidana penjara paling lama tiga bulan atau di dalam pembuatan visum et repertum termasuk ke dalam luka derajat pertama (luka golongan C); apabila "penganiayaan” itu menimbulkan luka yang memerlukan perawatan sementara waktu sebagaimana ditentukan di dalam Pasal 351 (1) KUHP, di dalam pembuatan visum et repertum termasuk ke dalam luka derajat kedua (golongan B); dan apabila "penganiayaan" itu menimbulkan luka yang mengakibatkan luka berat sehingga terhalang dalam menjalankan jabatan atau pekerjaan yang bersifat tetap/permanen atau penyakit atau luka yang tak dapat diharapkan akan sembuh secara sempurna, menurut 
KUHP merupakan penganiayaan berat (diatur dalam Pasal 351 (2) KUHP) atau Pasal 354 ayat (1), di dalam pembuatan visum et repertum termasuk ke dalam luka derajat ketiga (golongan A). ${ }^{9}$

b. Apabila BDSM Menyebabkan Hilangnya Nyawa

Seperti pada kasus sepasang suami istri di Batam yaitu Andana Wisnu dan Selvi yang berhubungan seksual yang diiringi oleh BDSM. Keduanya sama-sama tertarik dengan BDSM namun pada saat itu, Andana Wisnu melakukan dengan keadaan dibawah pengaruh sabu-sabu dan dipicu oleh perasaan cemburu ketika Selvi menyebutkan nama lelaki lain pada saat berhubungan sehingga BDSM dilakukan diluar batas dan menyebabkan kematian. Menurut Visum et Repertum, luka dari kegiatan BDSM tersebut bukan faktor utama kematian Selvi, namun menjadi pemercepat kematian Selvi. Hal tersebut dapat dikenai pasal penganiayaan menyebabkan mati yaitu Pasal 351 ayat (3) KUHP.

c. Apabila BDSM Dilakukan dengan Paksaan atau Tanpa Consent

Seperti yang telah dibahas pada sub bab 2.1, BDSM membutuhkan persetujuan atau consent. Sehingga apabila BDSM dilakukan tanpa persetujuan terlebih dahulu dan dilakukan dengan pemaksaan maka dapat digolongkan sebagai pemerkosaan atau pencabulan. Pasal yang dapat dikenakan atas perbuatan tersebut adalah pasal-pasal sebagai berikut:

\section{1) 285 KUHP}

Barang siapa dengan kekerasan atau ancaman kekerasan memaksa seorang wanita bersetubuh dengan dia diluar perkawinan, diancam karena melakukan perkosaan dengan pidana penjara paling lama dua belas tahun.

2) $292 \mathrm{KUHP}$

Orang dewasa yang melakukan perbuatan cabul dengan orang lain sesama kelamin, yang diketahuinya atau sepatutnya harus diduganya belum dewasa, diancam dengan pidana penjara paling lama lima tahun.

9 ibid. [55-56]. 
d. Apabila BDSM menyebabkan luka-luka atau hilangnya nyawa karena kealpaannya

Walaupun telah dilakukan negosisasi dan mencapai kesepkatan, tidak menutup kemungkinan BDSM scene menimbulkan kerugian pada salah satu pihak. Kurangnya kontrol dan pengabaian safe word dapat menjadi salah satu faktor dari kealpaan saat BDSM scene. Pasal-pasal yang dapat dikenakan apabila terjadi kealpaan adalah:

1) Pasal 359 KUHP

Barang siapa karena kesalahannya (kealpaannya) menyebabkan orang lain mati, diancam dengan pidana penjara paling lama lima tahun atau pidana kurungan paling lama satu tahun.

2) Pasal 360 KUHP

(1) Barang siapa karena kesalahannya (kealpaannya) menyebabkan orang lain mendapatkan luka-luka berat, diancam dengan pidana penjara paling lama lima tahun atau pidana kurungan paling lama satu tahun.

(2) Barang siapa karena kesalahannya (kealpaannya) menyebabkan orang lain luka-luka sedemikian rupa sehingga timbul penyakit atau halangan menjalankan pekerjaan jabatan atau pencarian selama waktu tertentu, diancam dengan pidana penjara paling lama sembilan bulan atau pidana kurungan paling lama enam bulan atau pidana denda paling tinggi empat ribu lima ratus rupiah.

Seseorang dapat melaporkan tindakan BDSM bila dirasa merugikan. BDSM scene yang dilakukan tanpa kontrol dan konsep yang matang, dapat menyebabkan luka, cacat atau bahkan kematian. BDSM scene yang dilakukan dengan consent tidak dapat dipidanakan karena dilakukan dengan persetujuan dan dengan kehatihatian. Selain itu, BDSM adalah hak setiap orang yang memiliki ketertarikan dalam kegiatan tersebut selama tidak membuat kerugian pada orang lain.

\section{Kemampuan Bertanggungjawab Pelaku BDSM}

Hukum pidana memiliki komponen sentral di dalamnya yang membedakan hukum pidana dengan hukum lainnya, yaitu perbuatan pidana, pertanggungjawaban pidana, serta pemidanaan. Pengertian perbuatan pidana tidak termasuk pengertian pertanggungjawaban pidana. Perbuatan pidana hanya menunjuk kepada dilarang dan diancamnya perbuatan dengan suatu ancaman pidana. Apakah orang yang 
melakukan perbuatan yang dilarang kemudian dijatuhi pidana tergantung kepada apakah dalam melakukan perbuatan itu orang tersebut memilii kesalahan. ${ }^{10}$ Setiap perbuatan pasti ada pertanggungjawaban yang menjadi salah satu resiko atas perbuatan tersebut. Termasuk perbuatan pidana menimbulkan pertanggungjawaban pidana yang harus dilaksanakan oleh pelaku tindak pidana.

Menurut Moeljatno, perbuatan pidana dan pertanggungjawaban pidana adalah dua hal yang berbeda atau disebut sebagai ajaran dualisme. Sehingga, antara perbuatan (actus reus) dan sikap batin (mens rea) berhubungan. Atau dapat dikatakan tindakan harus didasarkan dengan sikap batin apakah dilakukan dengan sengaja atau kealpaan. ${ }^{11}$

Sadisme dan masokisme dalam DSM-V termasuk dalam Parafilia. Parafilia berasal dari kata "para" yaitu penyimpangan pada apa yang membuat orang tertarik ("philia"). ${ }^{12}$ Parafilia mengacu pada sekelompok gangguan yang mencakup ketertarikan seksual terhadap objek yang tidak wajar atau aktivitas seksual yang tidak pada umumnya. ${ }^{13}$ Seseorang mungkin akan menampilkan satu atau lebih parafilia dan pola ini mungkin merupakan aspek dari gangguan mental lain, seperti: skizofrenia, depresi, atau salah satu gangguan kepribadian. ${ }^{14}$

Dalam DSM-V, masokisme diberi kode 302.85 (F65.51) dan sadisme degan kode 302.84 (F65.52). Masokisme dalam DSM-V diberikan ciri diagnosa sebagai berikut: ${ }^{15}$

"Over a period of at least 6 months, recurrent and intense sexual arousal from the act of being humiliated, beaten, bound, or othenwise made to suffer, as manifested by fantasies, urges, or behaviors.

The fantasies, sexual urges, or behaviors cause clinically significant distress or impairment in social, occupational, or other important areas offunctioning.

\footnotetext{
${ }^{10}$ Moeljatno, Asas-Asas Hukum Pidana, (Rineka Cipta 2015).[165].

${ }^{11}$ Hanafi, 'Reformasi Sistem Pertanggungjawaban Pidana', (1999), 11 Ius Quia Iustum Law Journal of Islamic Univesity of Indonesia. [30].

12 Fatmawati Fadli, dkk., Bunga Rampai: Apa itu Psikopatologi "Rangkaian atatan Ringkas Tentang Gangguan Jiwa", (Unimal Press 2019).[71].

${ }^{13}$ ibid.

14 ibid.

15 American Psychiatric Association, Diagnostic and Statistical Manual of Mental Disorders Fifth Edition DSM-5, (American Psychiatric Publishing 2013).[694].
} 
a. Specify if: With asphyxiophilia: If the individual engages in the practice of achieving sexual arousal related to restriction of breathing.

b. Specify if: In a controlled environment: This specifier is primarily applicable to individuals living in institutional or other settings where opportunities to engage in masochistic sexual behaviors are restricted. In full remission: There has been no distress or impairment in social, occupational, or other areas of functioning for at last 5 years while in an uncontrolled environment".

Sedangkan untuk sadisme dengan kriteria sebagai berikut: ${ }^{16}$

"Over a period of at least 6 months, recurrent and intense sexual arousal from the physical or psychological suffering of another person, as manifested by fantasies, urges, or behaviors.

The individual has acted on these sexual urges with a nonconsenting person, or the sexual urges or fantasies cause clinically significant distress or impairment in social, occupational, or other important areas of functioning.

a. Specify if: In a controlled environment: This specifier is primarily applicable to individuals living in institutional or other settings where opportunities to engage in sadistic sexual behaviors are restricted.

b. In full remission: The individual has not acted on the urges with a nonconsenting person, and there has been no distress or impairment in social, occupational, or other areas of functioning, for at least 5 years while in an uncontrolled environment".

Pelaku BDSM scene yang menimbulkan kerugian wajib dilaporkan untuk mempertanggungjawabkan perbuatannya. Mereka yang melakukan perbuatan tersebut secara sadar baik disengaja atau karena kealpaan wajib dipidana sesuai dengan delik yang diperbuat. Pelaku dinyatakan memiliki kesalahan apabila:

a. Melakukan Perbuatan Pidana

Meskipun BDSM identik dengan perlakuan menyiksa sseorang, namun BDSM tidak dapat disebut sebagai perbuatan pidana karena dilakukan atas dasar kesepakatan. BDSM dapat dinyatakan sebagai perbuatan pidana dan memiliki kesalahan apabila melakukan perbuatan yang mengandung unsur melawan hukum dan dilarang oleh undang-undang seperti menganiaya tanpa adanya kesepakatan atau lebih dari yang disepakati dan/membunuh lawan mainnya.

${ }^{16}$ ibid.[695]. 
b. Diatas Umur Tertentu dan Mampu Bertanggungjawab (Kemampuan Bertanggungjawab)

Pelaku yang berada di bawah umur akan dipidana sesuai dengan UU SPPA. Berdasarkan Pasal 21 ayat (1) UU SPPA, anak yang berusia dibawah 12 tahun akan dikembalikan kepada orangtua/wali atau diikutsertakan dalam program pendidikan, pembinaan, dan pembimbingan di instansi pemerintah atau LPKS di instansi yang menangani bidang kesejahteraan sosial, baik di tingkat pusat maupun daerah, paling lama 6 (enam) bulan. Berdasarkan Pasal 81 ayat (2) UU SPPA anak dijatuhi pidana penjara maka paling lama adalah $1 / 2$ dari ancaman hukuman orang dewasa dan berdasarkan Pasal 81 ayat (6) apabila ancaman pidana dalam undang-undang adalah pidana penjara seumur hidup atau hukuman mati, maka pidana yang dijatuhkan maksimal 10 tahun.

Setiaporangyangmelakukantindakpidanaharusmempertanggungjawabkan perbuatannya. Dikecualikan kepada seseorang yang memiliki gangguan kejiwaan sebagaimana disebutkan dalam Pasal 44 KUHP maka seseorang tersebut tidak dipidana. Sadisme dan masokisme merupakan penyimpangan kejiwaan namun bukan termasuk kedalam kriteria jiwa yang cacat dalam pertumbuhan (gebrekkige ontwikkeling) atau terganggu karena penyakit (ziekelijke storing) sehingga untuk pelaku BDSM yang melakukan tindak pidana tidak dapat digugurkan pemidanaannya dengan Pasal 44 KUHP. Pelaku akan tetap dipidana sesuai dengan perbuatan yang ia lakukan karena diluar jiwanya yang menyimpang ia dapat memenuhi unsur-unsur orang yang mampu bertanggung jawab yaitu: ${ }^{17}$

1. Mampu menentukan niat, kehendak, rencana atas perbuatan yang dilakukan;

2. Mengetahui bahwa perbuatannya dipandang tidak patut oleh masyarakat;

3. Mengetahui arti, makna hakikat dari perbuatan bahwa perbuatannya baik atau buruk.

c. Mempunya suatu bentuk kesalahan yang berupa kesengajaan atau kealpaan.

BDSM dilakukan dengan kesepakatan dan seluruh aktifitasnya telah diperjanjikan sebelumnya. Sengaja atau alpanya seseorang melakukan perbuatan

\footnotetext{
${ }^{17}$ Didik Endro Purwoleksono, Hukum Pidana, (Airlangga University Press 2014).[68].
} 
diluar perjanjian dapat dinilai dari mes rea pelaku. Apabila pelaku menyadari dan menghendaki penganiayaan atau pembunuhan dengan media BDSM maka perbuatan tersebut adalah sengaja. Namun apabila pelaku tidak menghendaki dan terjadi kecelakaan saat BDSM scene secara tidak terduga, maka perbuatan tersebut adalah alpa.

d. Tidak adanya alasan pemaaf

Berdasarkan penjelasan pada poin nomor 3, BDSM yang dilakukan oleh seseorang yang memiliki penyimpangan kejiwaan sadisme dan masokisme bukan termasuk dalam alasan penggugur pemidanaan. Sehingga, tidak ada alasan pemaaf dan pendengar untuk pelaku BDSM yang menyebabkan luka, cacat dan hilangnya nyawa.

Kasus mengenai BDSM yang menyebabkan luka, cacat dan hilangnya nyawa telah banyak terjadi di luar negeri. Di Indonesia sendiri kasus yang melibatkan sadisme dan masokisme sudah pernah terjadi. Namun, kasus tersebut berakhir di Pengadilan Agama sebagai kasus perceraian. Contoh kasus yang berakhir di Pengadilan Negeri adalah kasus Andana Wisnu Anggoro atau Derbi (selanjutnya disebut dengan terdakwa) yang berhubungan suami istri dengan istrinya Selvi Puji Kristanti dengan melibatkan BDSM scene dan berakibat hilangnya nyawa Selvi Puji Kristianti dalam Putusan Nomor 32/Pid.B/2019/PN.Btm.

Kasus tersebut merupakan salah satu kelalaian dalam mempraktekkan hubungan seksual atau scene yang mengandung BDSM. Ketika terdakwa melakukan penamparan dan penjambakan seperti yang ia lakukan biasanya dan dengan consent, tidak akan menjadi masalah. Akan tetapi jika terdakwa melakukan diluar batas consent dan diluar kontrol dengan keadaan sedang dipengaruhi oleh sabu-sabu serta perasaan cemburu akibat Selvi memanggil nama mantan kekasihnya, maka hal tersebut dapat merugikan Selvi dan berakibat kematian. Sehingga perbuatan terdakwa digolongkan menjadi suatu tindak pidana.

Selain itu diperkuat dengan kesaksian Handyanna Prathitha Rahayu mantan istri dari terdakwa, terdakwa dulunya setiap melakukan hubungan Intim terhadap saksi melakukan pemukulan dibagian bokong (pantat), cekik leher, menjambak 
rambut dan mengikat kedua tangan saksi dengan menggunakan tali pinggang/sabuk. Pernyataan tersebut memperkuat dugaan bahwa terdakwa memiliki ketertarikan pada hal-hal yang berkaitan dengan BDSM.

Menurut Visum et Repertum, didapatkan luka akibat kekerasan tumpul, berupa luka memar hampir diseluruh tubuh;luka lecet pada dada. Penyebab utama kematian Selvi adalah kekerasan tumpul pada leher yang mengakibatkan patahnya tulang leher. Luka-luka memar dan lecet yang ada disekujur tubuh Selvi tidak bersifat mematikan secara tersendiri, namun luka-luka dalam jumlah yang banyak ini memiliki andil dalam menimbulkan kematian korban.

Berdasarkan fakta-fakta dan bukti-bukti yang tertera dalam lampiran maupun persidangan, terdakwa terlihat sehat secara mental dan raga sehingga dianggap mampu mempertanggungjawabkan perbuatannya serta tidak ditemukan alasan pemaaf atau pembenar untuk menggugurkan pemidanaan.

Perbuatan terdakwa dalam kronologi yang dijelaskan memenuhi unsur dakwaan kedua yaitu Pasal 351 ayat (3) KUHP tentang penganiayaan yang mengakibatkan mati. Pertimbangan-pertimbangan hakim dalam memberikan pemidanaan dinilai telah tepat dan menghasilkan putusan pemidanaan 6 tahun penjara dan biaya perkara sebesar Rp 5.000,-.

\section{Kesimpulan}

BDSM bukan merupakan tindak pidana walaupun sangat erat kaitannya dengan kekerasan. Hal tersebut dikarenakan BDSM dilakukan dengan consent atau persetujuan. Consent inilah benang merah dari dibedakannya BDSM dengan kekerasan dalam hubungan seksual.

Pelaku BDSM dapat dikenakan pemidanaan apabila menimbulkan kerugian seperti cacat, luka atau kematian. Pelaku tersebut dipidana sesuai dengan hal-hal yang diperbuat dan fakta dalam persidangan. BDSM erat kaitannya dengan sadisme dan masokisme. Dalam ilmu kejiwaan yang dituangkan dalam buku DSM-V, sadisme dan masokisme termasuk dalam parafilia. Namun, penyimpangan kejiwaan tersebut tidak dapat dijadikan sebagai alasan untuk menggugurkan pemidanaan dikarenakan 
bukan termasuk yang dikecualikan pada Pasal 44 KUHP. Sehingga, pelaku BDSM yang menyebabkan luka, cacat dan hilangnya nyawa akan tetap dipidana.

\section{Daftar Bacaan}

\section{Buku}

American Psychiatric Association, Diagnostic and Statistical Manual of Mental Disorders Fifth Edition DSM-5, (American Psychiatric Publishing 2013).

Didik Endro Purwoleksono, Hukum Pidana, (Airlangga University Press 2014).

Fatmawati Fadli, dkk., Bunga Rampai: Apa itu Psikopatologi "Rangkaian catatan Ringkas Tentang Gangguan Jiwa” (Unimal Press 2019).

Moeljatno, Asas-Asas Hukum Pidana (Rineka Cipta 2015).

Tristan Taormino, Ultimate Guide to Kink (Cleiss Press 2015).

\section{Jurnal}

DR.Y.A. Triana Ohoiwutun, 'Ilmu Kedokteran Forensik (Interaksi dan Dependensi Hukum pada Ilmu Kedokteran)', (2017), Repository Universitas Jember (online).

Hanafi, 'Reformasi Sistem Pertanggungjawaban Pidana', (1999), 11 Ius Quia Iustum Law Journal of Islamic Univesity of Indonesia.

\section{Laman}

Boy Denon, 'BDSM as an Art Form', (Deviance \& Desire, 19 Februari 2016), $<$ https://www.devianceanddesire.com/2016/02/bdsm-as-an-art-form/>, diakses pada 15 Oktober 2020.

Nicholas R., 'Arisan 11! BDSM', (Support Group and Resource Center on Sexuality Studies, 27 September 2015), $<$ http://sgrcui.wordpress.com $>$, diakses pada tanggal 7 Agustus 2020.

Tim CNN Indonesia, 'Mengenali Beda BDSM dan Kekerasan Seksual', (CNN Indonesia, 29 Februari 2020), <https://www.cnnindonesia.com/gayahidup/20200225151318-284-477975/mengenali-beda-bdsm-dan-kekerasanseksual>, diakses pada 7 Agustus 2020 . 
Elok Fauzia: Pertanggungjawaban Pidana Pelaku...

\section{Perundang-undangan}

Kitab Undang-Undang Hukum Pidana.

Undang-Undang Republik Indonesia Nomor 11 Tahun 2012 Tentang Sistem Peradilan Pidana Anak.

Undang-Undang Republik Indonesia Nomor 23 Tahun 2004 Tentang Penghapusan kekerasan Dalam Rumah Tangga,

Undang-Undang Nomor 31 Tahun 2014 Tentang Perubahan Atas Undang-Undang Nomor 13 Tahun 2006 Tentang Perlindungan Saksi dan Korban. 